\title{
Desarrollo procedimental de las controversias en seguridad social
}

\author{
Procedural development of social security disputes \\ Verónica Lidia Martínez Martínez \\ marb cap@hotmail.com \\ Universidad Anáhuac, Campus Norte de la Ciudad de México
}

Recibido: Abril 2018 / Revisado: Mayo 2018 / Aceptado: Junio 2018/ Publicado: Julio 2018

\begin{abstract}
RESUMEN
Esta investigación tiene como objetivos analizar la anomia, deficiencias y contradicciones existentes en la Constitución mexicana y en la legislación laboral, en lo concerniente a los conflictos de seguridad social. La investigación de tipo documental y teórica-descriptiva, apoyada en la teoría de los ámbitos de validez de la norma de Hans Kelsen, expone como principales problemas la falta de reconocimiento constitucional de las controversias de seguridad social y su equívoca regulación en la legislación laboral bajo el procedimiento de naturaleza especial. Por supuesto, fue fundamental el análisis de las iniciativas de reforma que se han propuesto con la finalidad de crear la normatividad secundaria que reglamente la judicialización de la justicia laboral aprobada en 2017. Desde el punto de vista metodológico, la investigación requirió de la consulta de fuentes especializadas en derecho laboral, derecho de la seguridad social y teoría del derecho bajo el amparo de los métodos deductivo y comparado, nos permitieron concluir que los conflictos laborales y los conflictos de seguridad social deben regularse de manera independiente en la ley laboral y en las leyes de seguridad social respectivamente, encomendándose su tramitación y resolución a organismos especializados en esas materias pues, a pesar de formar parte del derecho social, sus ámbitos objetivos, subjetivos y normativos son diversos; además, de tener instituciones propias y responder a necesidades disimiles que hacen necesaria una regulación procedimental acorde con su naturaleza y principios jurídicos.
\end{abstract}

Palabras clave: Justicia laboral, conflictos de seguridad social, derecho laboral, derecho de la seguridad social, procedimientos
ABSTRACT

Taking as a frame of reference the labor reform carried out in Mexico in 2017, this research has as objectives to analyze the anomie, deficiencies and contradictions existing in the Mexican Constitution and in labor legislation regarding social security conflicts. The investigation of documentary and theoreticaldescriptive type, supported by the theory of the areas of validity of the Hans Kelsen standard, exposes as main problems the lack of constitutional recognition of social security disputes and its ambiguous regulation in the labor legislation under the procedure of special nature. Of course, the analysis of the reform initiatives that have been proposed with the purpose of creating the secondary regulations that regulate the judicialization of labor justice approved in 2017 was fundamental. From the methodological point of view, the investigation required the consultation of specialized sources in labor law, social security law and theory of law under the protection of deductive and comparative methods, allowed us to conclude that labor conflicts and social security conflicts should be regulated independently in the labor law and in the social security laws respectively, entrusting their processing and resolution to specialized agencies in these matters because, despite being part of social law, its objective, subjective and regulatory areas are diverse; in addition, to have their own institutions and respond to dissimilar needs that make procedural regulation necessary according to their nature and legal principles.

Key words: labor justice, social security conflicts, labor law, social security law, procedures 
INTRODUCCIÓN

El 28 de abril de 2016 el ejecutivo federal presentó ante la Cámara de Senadores del Congreso de la Unión la iniciativa de Decreto por el que se reforman y adicionan diversas disposiciones de la Constitución Política de los Estados Unidos Mexicanos, en materia de justicia laboral. La iniciativa presidencial propuso una reforma al derecho procesal del trabajo que descansaba en dos premisas básicas: (Cámara de Diputados, 2016, p. 6): a. El replanteamiento de la función conciliatoria, de manera que constituya una instancia prejudicial a la cual los trabajadores y patrones deberán acudir. b. La justicia laboral sea impartida en lo sucesivo por órganos del Poder Judicial Federal o de los poderes judiciales locales, según corresponda. Así, ambas propuestas hoy son una realidad ante la aprobación del Decreto por el que se declaran reformadas y adicionadas diversas disposiciones de los artículos 107 y 123 de la
Constitución Política de los Estados Unidos Mexicanos, en materia de justicia laboral, publicado en el Diario Oficial de la Federación el 24 de febrero de 2017.

En tal sentido, en el ámbito procesal, el Decreto por el que se declaran reformadas y adicionadas diversas disposiciones de los artículos 107 y 123 de la Constitución Política de los Estados Unidos Mexicanos, en materia de justicia laboral presenta dos principales problemas: El primero de los inconvenientes consiste en la falta de reconocimiento constitucional de los conflictos de seguridad social, a pesar de que al día de hoy, la Junta Federal de Conciliación y Arbitraje se encarga de su tramitación y resolución, como lo demuestra la base estadística que reportan las 66 Juntas Especiales que componen la Junta Federal de Conciliación y Arbitraje, los conflictos individuales de seguridad social interpuestos al 31 de julio de 2017.

Cuadro 1. Conflictos individuales de seguridad social interpuestos al 31 de julio de 2017

\begin{tabular}{|c|c|c|c|c|c|}
\hline \multirow{2}{*}{ Fases } & \multirow{2}{*}{$\begin{array}{c}\text { Total de } \\
\text { asuntos } \\
\text { laborales }\end{array}$} & \multicolumn{3}{|c|}{ SEGURIDAD SOCIAL } & \multirow{2}{*}{$\begin{array}{c}\text { Total de asuntos } \\
\text { de seguridad } \\
\text { social }\end{array}$} \\
\hline & & IMSS & AFORES & INFONAVIT & \\
\hline Instrucción & 138,669 & 40,625 & 15,869 & 3,246 & 59,740 \\
\hline Dictamen & 38,451 & 21,673 & 9,987 & 2,401 & 34,061 \\
\hline Amparo & 33,066 & 8,105 & 2429 & 411 & 10,945 \\
\hline Laudo & 33,118 & 15,379 & 25,816 & 4,170 & 45,365 \\
\hline Ejecución & 19,444 & 14,075 & 13,921 & 1,925 & 29,921 \\
\hline Total & 262,748 & 99,857 & 68,022 & 12,153 & 180,032 \\
\hline
\end{tabular}

Fuente: Elaborado por la Autora, sobre la base en la información estadística proporcionada por la Junta Federal de Conciliación y Arbitraje al 30 de julio de 2017.

En tanto que, el segundo problema consiste en el incumplimiento al artículo segundo transitorio del referido Decreto, que dispone que el Congreso de la Unión y las legislaturas de las entidades federativas deberán realizar las adecuaciones legislativas que correspondan dentro del año siguiente a la entrada en vigor del mismo, esto es, al 25 de febrero de 2018. (Cámara de Diputados, 2017, p. 3). Por lo que, hasta este momento en México, en contravención al artículo segundo transitorio del decreto del 24 de febrero de 2017, no se han creado los órganos del Poder Judicial Federal, ni de los poderes judiciales locales que tendrán a su cargo la tramitación y resolución de las controversias laborales, como tampoco se ha expedido el ordenamiento que regule la parte 
procedimental de la reforma constitucional ante la judicialización de la justicia laboral en México.

Tal y como se expone en este estudio, que tiene por objetivo general analizar la anomia, deficiencias y contradicciones existentes en la Constitución mexicana y en la legislación laboral en lo concerniente a los conflictos de seguridad social, se han presentado tres iniciativas para materializar la reforma constitucional de 2017, pero sólo dos de ellas están dirigidas a reglamentar la interposición, tramitación y resolución de las controversias de seguridad social mediante procedimientos especules laborales, lo cual constituye el segundo problema que se aborda en este trabajo con base en la teoría de los ámbitos de validez de la normas jurídicas sostenida principalmente por Hans Kelsen.

$\mathrm{Y}$ es que a pesar de que el derecho laboral y el derecho de la seguridad social son parte del derecho social, sus marcos teóricos y jurídicos, instituciones, objetos de protección, elementos subjetivos y objetivos al ser disimiles ameritan de una regulación propia y de órganos especializados en su resolución. De nueva cuenta la reforma laboral del 2017 viene a reiterar el perenne error en el que hemos vivido: someter el derecho de la seguridad social al derecho laboral, cuando la realidad nos ha demostrado que su contenido es insuficiente para dar cuenta del multifacético y evolutivo derecho de la seguridad, cuya mayoría de edad e independencia del derecho obrero es más que evidente en el mundo fáctico y jurídico, por lo que amerita tener una regulación especializada en la Ley del Seguro Social y en la Ley del Instituto de Seguridad y Servicios Sociales de los Trabajadores del Estado

\section{Importancia del problema}

Los derechos a organización y procedimiento resultan ser los medios para producir un resultado acorde con los derechos fundamentales $y$, con ello, asegurar eficazmente tales derechos en vista de la problemática moderna (Alexy, 2002, p. 468.). De tal forma que, os procedimientos al ser sistemas de reglas o principios para la obtención de un resultado, cuando éstos se producen conforme a los parámetros establecidos, entonces, desde el aspecto procedimental presentan una característica positiva. Si no es obtenido de esta manera, entonces es defectuoso desde el punto de vista procedimental $\mathrm{y}$, por ello, tiene una característica negativa (Alexy, 2002, p. 457). Es indispensable que todo derecho sustantivo o material no sólo se respete, sino que se instituyan los mecanismos procesales para su protección jurídica efectiva que garanticen al individuo la posibilidad de acceder a instancias jurisdiccionales y administrativas ante su violación.

La ausencia de procedimientos en la Ley del Seguro Social y en la Ley del Instituto de Seguridad y Servicios Sociales de los Trabajadores del Estado constituye uno de los principales obstáculos para lograr que los asegurados, pensionados y sus beneficiarios puedan acceder a las prestaciones en dinero y en especie establecidas en cada uno de los seguros sociales, las cuales deben otorgarse con la debida oportunidad y prontitud, debido a que el primer tipo de beneficios, en la mayoría de los casos, son sustitutivas del salario ante la imposibilidad del asegurado de laborar; en tanto que las prestaciones en especie su finalidad es restituir la salud del derechohabiente o proveer de los medios para atender y controlar los padecimientos, secuelas y limitaciones que sean irreversibles. De ahí que el derecho a la seguridad social al involucrar una serie de prestaciones básicas e indispensables para asegurar la subsistencia digna del individuo y de su familia constituye una parte fundamental del mínimo vital. Pero, con independencia de la finalidad de las prestaciones de seguridad social, no debemos olvidar que no se trata de derechos de papel, ni dádivas gubernamentales o ingresos de los 
organismos de seguridad social, sino de auténticos derechos adquiridos y financiados por todos los que contribuyen para su permanencia y capitalización, por lo que, cumplidos los requisitos consignados en las leyes de seguridad social, deben otorgarse a sus legítimos titulares.

\section{METODOLOGÍA}

Desde el punto de vista metodológico, la investigación de tipo documental y a nivel teórico-descriptivo comienza con el análisis de la Exposición de Motivos del Decreto por el que se reforman $y$ adicionan diversas disposiciones de la Constitución Política de los Estados Unidos Mexicanos, en materia de justicia laboral, debido a que en este documento se expusieron las razones que detonaron el cambio de paradigma en el derecho procesal del trabajo, al decretarse la creación de los tribunales laborales dependientes del Poder Judicial Federal y de los poderes judiciales a nivel local, a los que se encomienda la tramitación y resolución de las controversias laborales en sustitución de las Juntas de Conciliación y Arbitraje dependientes del ejecutivo federal, olvidándose de la regulación de los conflictos de seguridad social.

De igual manera, una parte medular del trabajo lo constituyó la revisión de las iniciativas que se han presentado ante la Cámara de Senadores durante los años de 2017 y 2018, las cuales tienen como objetivo la creación del marco institucional y procedimental, bajo los que se han de tramitar y resolver los conflictos laborales y las controversias de seguridad social ante el nuevo modelo de justicia laboral implantado como resultado de la reforma constitucional aprobada en México en 2017.

En cuanto al material documental empleado en esta investigación fue el relativo al derecho procesal del trabajo y el derecho de la seguridad social, así como el existente en el ámbito de la teoría del derecho. A pesar de resultar escasa la literatura en lo referente a los conflictos de seguridad social y a la reforma laboral de 2017, las fuentes bibliohemerográficas fueron útiles para identificar los elementos normativos, subjetivos y objetivos del derecho de la seguridad social y del derecho laboral, así como establecer las principales características de los conflictos laborales y de los conflictos de seguridad social para proceder a su diferenciación.

Dentro de la teoría del derecho la revisión de lo que doctrinalmente se ha denominado como anomia constitucional y la teoría de los ámbitos de validez de la normas jurídicas fue fundamental, ya que por una parte, nos permitió exponer las principales deficiencias de la reforma laboral aprobada en 2017 en lo concerniente a la interposición, tramitación y resolución de los conflictos de seguridad social, y por la otra, fue empleada para proponer las posibles soluciones a la problemática que se expone en este trabajo.

\section{RESULTADOS}

Ante la judicialización de la justicia laboral instaurada por la reforma constitucional de 2017, en la que se encomienda la resolución de las diferencias entre trabajadores y patrones a los tribunales laborales del Poder Judicial de la Federación o a los poderes judiciales de las entidades federativas, según corresponda, concretamente el artículo segundo transitorio del Decreto por el que se reforman y adicionan diversas disposiciones de la Constitución Política de los Estados Unidos Mexicanos, en materia de justicia laboral, publicado el 24 de febrero de 2017 en el Diario Oficial de la Federación, dispone que el Congreso de la Unión y las legislaturas de las entidades federativas deben realizar las adecuaciones legislativas que correspondan para dar cumplimiento a lo previsto en el referido Decreto, dentro del año siguiente a la entrada en vigor del mismo, esto es, al 25 de 
febrero de 2018 (Cámara de Diputados, 2018, p. 3)

Al día de hoy, para cumplimentar la reforma laboral en materia de justicia laboral, las legislaturas de los Estados de Aguascalientes, Campeche, Chiapas, Chihuahua, Coahuila, Estado de México, Hidalgo, Jalisco, Michoacán, Nayarit, Nuevo León, Quintana Roo, Sinaloa, Sonora, Tamaulipas, Tlaxcala y Zacatecas se han limitado en sus textos constitucionales a atribuir a los poderes judiciales de las Entidades Federativas competencia para tramitar y resolver los conflictos entre trabajadores y patrones, existiendo un vacío legal en lo concerniente a la interposición, tramitación y resolución de las controversias de seguridad social.

En cuanto a la expedición de la ley secundaria que haga operativa la reforma constitucional en materia de justicia laboral se han presentado ante la Cámara de Senadores tres iniciativas legislativas durante los años de 2017 y 2018.

Bajo la denominación de Iniciativa con proyecto de Decreto por el que se reforman la Ley de Amparo, adecuando la reforma del artículo 107 constitucional a su ley reglamentaria y la Ley Federal del Trabajo, el senador Luis Sánchez Jiménez la presentó en 2017 ante la Cámara de Senadores. En este documento se retoma el procedimiento especial laboral destinado al reclamo de las prestaciones establecidas en los seguros de maternidad, retiro, cesantía en edad avanzada, guarderías y prestaciones sociales pertenecientes al régimen obligatorio que regula la Ley del Seguro Social y sus disposiciones reglamentarias, así como el procedimiento especial laboral para demandar las prestaciones del seguro de riesgos de trabajo, enfermedades e invalidez que reglamentan dichas disposiciones normativas, tal y como fueron instaurados en la reforma laboral de 2012, pero su resolución estará a cargo del Tribunal Laboral Unitario de Circuito en sustitución de las Juntas Especiales que integran la Junta Federal de Conciliación y Arbitraje (Cámara de Diputados, 2017, pp. 1-198).

De esta manera, tratándose del primer tipo de controversias de seguridad social, constituyen la expresión más rotunda de la concentración procesal, pues salvo que se hayan ofrecido pruebas en la demanda y contestación que ameriten desahogo especial, este tipo de reclamos se plantean en la primera audiencia --única en términos generales-- en la que se celebran las etapas de conciliación, demanda y excepciones, pruebas y resolución.

En el caso concreto de los conflictos individuales de seguridad social interpuestos para demandar las prestaciones derivadas de riesgos profesionales, enfermedades generales o un estado de invalidez, el procedimiento tendrá ciertas peculiaridades ante la naturaleza de las probanzas que se ofertan, las cuales se trata principalmente de periciales médicas, periciales técnicas y visitas armadas al último centro de trabajo del asegurado o pensionado. De entrada, las partes designarán a sus peritos médicos en la demanda y en la contestación de la misma, teniendo un plazo de diez días hábiles contados a partir de la celebración de la audiencia inicial para que los peritos acepten y protesten el cargo conferido y expresen en forma justificada los requerimientos necesarios para la emisión del correspondiente dictamen (Cámara de Diputados, 2017, p. 161).

Dentro de los treinta días siguientes a la celebración de la audiencia inicial, el Tribunal Laboral Unitario de Circuito señalará día y hora para la audiencia, en la que con citación de las partes se recibirán los dictámenes periciales de aquellos peritos que se encuentren inscritos en el registro del Tribunal Laboral Unitario de Circuito. Al concluir el desahogo de todas probanzas ofrecidas por las partes, el tribunal escuchará 
los alegatos y deberá dictar la resolución que ponga fin al conflicto interpuesto (Cámara de Diputados, 2017, p. 162).

Por su parte, los senadores Tereso Medina Ramírez e Isaías González Cuevas presentaron el 7 de diciembre de 2017 ante la Cámara de Senadores, la Iniciativa con proyecto de decreto por el que se expide la Ley del Instituto Federal de Conciliación y Registro Laborales; y se reforman, adicionan y derogan diversas disposiciones de la Ley Federal del Trabajo, de la Ley Federal de Entidades Paraestatales; de la Ley Orgánica de la Administración Pública Federal; de la Ley del Seguro Social y de la Ley del Instituto del Fondo Nacional de la Vivienda para los Trabajadores, en materia de justicia laboral (Cámara de Diputados, 2017, pp. 1286).Conforme al texto de esta iniciativa, se retoman las bases de los dos procedimientos especiales laborales destinados al reclamo de las distintas prestaciones, derivadas de los seguros sociales integrantes del régimen obligatorio que regula la Ley del Seguro Social y sus disposiciones reglamentarias; pero, propone los cambios siguientes: Admitida la demanda con los documentos y copias requeridas, se correrá traslado a la parte demandada, quien deberá contestarla dentro de los cinco días siguientes a la fecha del emplazamiento. Del escrito de contestación se dará vista a la parte actora por el término de tres días para que manifieste lo que a su derecho convenga (Cámara de Diputados, 2017, p. 244).

Desahogada la vista de la contestación a la demanda o transcurridos los plazos para ello, el Tribunal Especializado en Seguridad Social del Poder Judicial de la Federación dictará acuerdo en el que fijará día y hora para la celebración de la audiencia de juicio, que deberá efectuarse dentro de los veinte días siguientes. En el mismo auto el tribunal deberá admitir o desechar las probanzas ofrecidas por las partes, fijando la forma de preparación de las mismas, a efecto de que se desahoguen a más tardar en la audiencia de juicio, sin que ésta pueda diferirse por ninguna circunstancia, salvo caso fortuito o fuerza mayor Cámara de Diputados, 2017, p. 244). En la audiencia de juicio, después de que el Tribunal Especializado en Seguridad Social del Poder Judicial de la Federación haya depurado el procedimiento y en su caso hubiera resuelto las excepciones procesales planteadas, se procederá al desahogo de las pruebas ofrecidas y admitidas. En ningún caso por falta de preparación o desahogo de las pruebas admitidas se suspenderá ni diferirá la audiencia (Cámara de Diputados, 2017, p. 245).

Al concluir el desahogo de las pruebas, las partes alegarán lo que a su derecho convenga y el Tribunal Especializado en Seguridad Social del Poder Judicial dictará de inmediato la resolución correspondiente. (Cámara de Diputados, 2017, p. 246). Por último, la tercera iniciativa, presentada el 15 de febrero de 2018 ante el Senado de la República Mexicana, por los senadores Pilar Ortega Martínez, Teresa Medina Ramírez, Ernesto Cordero Arroyo y Miguel Ángel Chico Herrera, a pesar de que se intitula como Iniciativa con Proyecto de Decreto por el que reforman y adicionan diversas disposiciones de las Leyes Federal del Trabajo, del Seguro Social y del Instituto de Seguridad y Servicios Sociales de los Trabajadores del Estado, no se ocupa de reglamentar ningún tipo de procedimiento para la interposición, tramitación y resolución de los conflictos laborales, ni de las controversias de seguridad social, por lo que se omite su estudio al no corresponder con los objetivos de esta investigación. Básicamente lo que esta última iniciativa propone es el otorgamiento de un período de licencia para las madres o padres trabajadores de niñas, niños y los adolescentes diagnosticados con cáncer de cualquier tipo (Cámara de Diputados, 2017, pp. 1-12). 
En este contexto, es que se procede a la revisión de las dos primeras iniciativas en lo referente al ámbito procedimental de las controversias de seguridad social. Partiendo de la Exposición de Motivos del Decreto por el que se declaran reformadas y adicionadas diversas disposiciones de los artículos 107 y 123 de la Constitución Política de los Estados Unidos Mexicanos, en materia de justicia laboral, presentado el 28 de abril de 2016 por el ejecutivo federal, se señaló expresamente lo siguiente:

Los cambios introducidos en la justicia laboral se sustentaron fundamentalmente en el establecimiento de mecanismos para eficientar los procedimientos acortando tiempos para que la justicia sea una realidad, y en la profesionalización del personal encargado de impartirla. No obstante, después de tres años y como resultado de concienzudas evaluaciones y análisis presentados en diferentes foros, se arriba a la conclusión que se requieren transformaciones cualitativas para que la justicia laboral cumpla su propósito. (Cámara de Senadores, 2016, p. 3)

Como puede advertirse, si el principal objetivo de la iniciativa de reforma laboral de 2017, según su exposición de motivos, fue la modificación de la justicia laboral, las iniciativas en las propone el seguir aplicando los procedimientos especiales instituidos en la reforma laboral de 2012 para resolver los conflictos individuales de seguridad social o la introducción de modificaciones a los mismos, provoca el incumplimiento al objetivo que motivó la aprobación de la reforma constitucional de 2017, teniendo como base los estudios de los foros temáticos organizados por el Centro de Investigación y Docencia Económicas en materia de justicia cotidiana, bajo la que se incluyó a la justicia civil, a la justicia de proximidad, a la justicia administrativa y a la justicia laboral (López
Ayllón, 2015, pp. 6-7). Y es que esta reforma, en al apartado A del artículo 123 constitucional, más que un cambio en el modelo de la justicia laboral ameritaba una transformación del paradigma de la justicia social, lo que implica no sólo la modificación de los procedimientos laborales consignados en la Ley Federal del Trabajo, sino el reconocimiento constitucional de las controversias de seguridad social para proceder a su regulacin procedimental dentro del marco jurídico del derecho de la seguridad social.

Los conflictos individuales de seguridad social, a los que se define como, las controversias que tienen por objeto reclamar actos u omisiones de los organismos de seguridad social que están relacionados con el reconocimiento de derechos 0 el otorgamiento de prestaciones derivadas de los diversos seguros que componen el régimen obligatorio del seguro social previsto en las diversas legislaciones de seguridad social, la Ley del Instituto del Fondo Nacional de la Vivienda para los Trabajadores con sus respectivos reglamentos, así como las que resulten aplicables en virtud de contratos colectivos de trabajo o contratos-Ley, al carecer de regulación en el texto constitucional son un ejemplo de lo que doctrinalmente se ha denominado como anomia constitucional.

La expresión anomia (Üvoìrá) empleada por Enrico Spagna Musso en su obra Appunti per una teoría dell' anomia constituzionale y utilizada por Peter Waldmann y Fernando Escalante Gonzalbo, Bernecker, 2004, con la que aluden a una omisión en las normas constitucionales de un hecho o situación que socialmente exigen ser regulados, es un neologismo introducido y desarrollado en las obras de Durkheim, conocidas bajo el nombre de la División del Trabajo Social (1998) y El Suicidio (1998) con una finalidad diversa, al referirse a un problema moral relacionado con el deterioro o rompimiento de lazos 
sociales y el decaimiento de la solidaridad.

La anomia constitucional, entendida como ausencia de normatividad, en comunión con el principio de legalidad --que dicta como máxima que el gobernado es libre de hacer todo aquello que la ley no prohíbe, mientras que los poderes públicos sólo pueden realizar aquello que la ley ordena- provocaría la inconstitucionalidad de las iniciativas propuestas en lo referente a los conflictos de seguridad social, debido a que no existe atribución en la norma suprema para materializar la regulación de este tipo de controversias.

A lo anterior, se adiciona que el sujetar la interposición, tramitación y resolución de los conflictos individuales de seguridad social bajo los lineamientos de los procedimientos especiales laborales, tal y como fueron instaurados en la reforma de 2012 y, ahora son retomados por las iniciativas presentadas por los senadores Luis Sánchez Jiménez, Tereso Medina Ramírez e Isaías González Cuevas, provoca la transgresión del objeto de la Ley Federal del Trabajo contenido en su artículo 10., que a la letra dispone: La presente Ley es de observancia general en toda la República y rige las relaciones de trabajo comprendidas en el artículo 123, Apartado A, de la Constitución. De la transcripción se sigue que el ordenamiento especializado en reglar las relaciones individuales y colectivas de naturaleza laboral lo es, sin lugar a dudas, la Ley Federal del Trabajo que reglamenta el apartado A del artículo 123 constitucional, debido a que en ella, se plasman una serie de derechos y obligaciones a cargo de los empleadores y los trabajadores, a quienes corresponde el derecho de acudir ante la autoridad laboral facultada expresamente en la norma constitucional--- para exigir el respeto, cumplimiento y exacta observancia de las disposiciones contenidos en el Código Obrero.

En tal sentido, tratándose de los conflictos individuales de seguridad social, al no existir una relación de trabajo, sino de órgano asegurador--asegurado entre los asegurados, pensionados y beneficiarios con los institutos de seguridad social que deriva del pago de las cuotas empleadas para el financiamiento de los seguros sociales que se otorguen ante el cumplimiento de una serie de requisitos, por consecuencia escapan de los ámbitos de validez material y personal de la legislación laboral.

De acuerdo con Kelsen (1995, p. 26), la norma jurídica puede tener un ámbito de validez espacial, lo que implica que resulta aplicable dentro de un determinado espacio. Por su parte, el ámbito de validez temporal, como su nombre lo indica, se refiere al tiempo en que una norma jurídica ha de reglar la realidad social o una parte de ella. Las normas jurídicas nacen a la vida jurídica a partir de una fecha determinada, que puede ser la de su entrada en vigor de una ley que se publica en un diario o periódico oficial $\mathrm{y}$, de igual manera, podrían tener una fecha en que dejan de estar en vigor (Kelsen, 1995, p. 26). Así, junto a estos dos ámbitos de validez de la norma, cabe también distinguir un dominio de validez personal y otro denominado objetivo o material. (Kelsen, 1995, p. 26). No obstante, que la Ley Federal Trabajo y las leyes de seguridad social, dentro de las cuales se encuentran la Ley del Seguro Social y la Ley del Instituto de Seguridad y Servicios Sociales de los Trabajadores al Servicio del Estado, se encuentran vigentes (ámbito temporal) y son de observancia general en toda la República Mexicana (ámbito espacial), sus ámbitos de validez material y personal son disímiles.

El ámbito de validez personal, entendido como a quien se dirige la legislación (Kelsen, 1995, p. 28) en el caso de la Ley Federal del Trabajo involucra a los empleadores y trabajadores inmersos en una relación de corte laboral, cuya nota distintiva es la subordinación. En tanto que, en el derecho a la seguridad social, en donde no es necesario la existencia de una relación laboral, para que 
tengan aplicabilidad las leyes de seguridad social, los elementos subjetivos son diversos a los del derecho laboral. Del tal forma que, ante el modelo de capitalización individual instituido en México, a partir del $1^{\circ}$ de julio de 1997, con la entrada en vigor de la actual Ley del Seguro Social y del 1으 de abril de 2007 al aprobarse la Ley del Instituto de Seguridad y Servicios Sociales de los Trabajadores al Servicio del Estado, el ámbito de validez personal del derecho a la seguridad social se amplía al involucrar no sólo al asegurado, al pensionado, a los beneficiarios y a los institutos de seguridad social, sino a los organismos financieros de índole privada, como las aseguradoras, las distintas Administradoras de Fondos para el Retiro y sus Sociedades de Inversión Especializadas de Fondos para el Retiro, cuya inexistencia y requisitos para su configuración dentro de la legislación laboral provocan la inaplicabilidad de esta última normatividad.

Ahora bien, en lo concerniente al ámbito de validez material, al que se conceptualiza como el contenido de la normatividad; en el derecho laboral este dominio se ocupa de la regulación de las relaciones de trabajo individuales y colectivas. En tanto que en el derecho de la seguridad social su dominio de validez material es el esquema de protección de los distintos seguros sociales que se encuentran reconocidos y regulados en las leyes de seguridad social. De tal manera que, si bien es adecuada la iniciativa presentada por el senador Luis Sánchez Jiménez, con base la fracción XX del apartado A del artículo 123 constitucional, proponga que se atribuya competencia a los tribunales laborales para tramitar y resolver las diferencias o los conflictos entre trabajadores y patrones; en lo concerniente a las controversias de seguridad social resulta inconstitucional que en la Ley Federal del Trabajo se determine que los conflictos de seguridad social estarán a cargo del Tribunal Laboral Unitario de Circuito, ante la anomia que existe en la Constitución mexicana y la inaplicabilidad de la legislación laboral, cuyo objeto y dominios de validez son diversos a los que rigen en las leyes de seguridad social. A pesar de la vinculación que existe entre el derecho de la seguridad social y el derecho laboral por razones de origen, al encontrar ambos su fundamento en el artículo 123 constitucional y ser partes integrantes del derecho social, los conflictos individuales de seguridad social, por su origen, naturaleza, características y ámbitos normativos para su resolución, son disímiles a los conflictos laborales. Las principales diferencias que existen entre los conflictos laborales y las controversias de seguridad social se resumen en el siguiente cuadro:

Cuadro 2. Diferencias entre conflictos laborales y conflictos de seguridad social

\begin{tabular}{lll}
\hline Diferencias & Conflictos laborales & Conflictos de seguridad social \\
\hline & & Asegurado \\
& Trabajador & Pensionado \\
Patrón & Beneficiario \\
Sindicato & Patrón o Sujetos obligados \\
& Estado & Administradoras de Fondos para el \\
& a) Intereses pugna: & Retiro Organismos de seguridad \\
& -Individuales y & Organismo asegurador vs \\
Tipos de conflictos & colectivos de carácter & Organismo asegurador vs \\
& jurídico & Pensionado \\
& -Individuales y & Organismo asegurador vs \\
& colectivos de carácter & Beneficiario \\
\hline
\end{tabular}

LEX. Revista de Investigación en Ciencias Jurídicas. Vol. 1, JNo. 1, Jufio-Septiembre, 2018 


\begin{tabular}{|c|c|c|}
\hline Diferencias & Conflictos laborales & Conflictos de seguridad social \\
\hline & $\begin{array}{l}\text { económico } \\
\text { b) Por los sujetos } \\
\text { Patrones vs } \\
\text { Trabajadores } \\
\text { Inter-obreros } \\
\text { Inter-patronales } \\
\text { Inter-sindicales } \\
\text { Trabajadores vs } \\
\text { Sindicatos } \\
\text { Sindicatos vs Estado } \\
\text { Sindicatos vs Terceras } \\
\text { personas }\end{array}$ & $\begin{array}{l}\text { Organismo asegurador vs } \\
\text { Organismo asegurador } \\
\text { Organismo asegurador vs Patrón } \\
\text { Organismo asegurador vs Sujeto } \\
\text { obligado } \\
\text { Afore vs Asegurado } \\
\text { Afore vs Pensionado } \\
\text { Afore vs Beneficiario }\end{array}$ \\
\hline $\begin{array}{l}\text { Tipo de relación } \\
\text { Prestaciones demandadas }\end{array}$ & $\begin{array}{l}\text { Laboral conforme a los } \\
\text { artículos } 20 \text { y } 21 \text { de la } \\
\text { Ley Federal del Trabajo } \\
\text { Laborales }\end{array}$ & $\begin{array}{l}\text { Asegurado-Órgano asegurador. } \\
\text { No es necesario que exista una } \\
\text { relación de trabajo } \\
\text { Depende del tipo de seguro que se } \\
\text { contrate con el organismo de } \\
\text { seguridad social } \\
\text { De seguridad social. } \\
\text { Sistema de Seguros Sociales } \\
\text { (pensiones vitalicias e } \\
\text { imprescriptibles) }\end{array}$ \\
\hline Marcos normativos & $\begin{array}{l}\text { Artículo 123, apartado A } \\
\text { Constitucional y } \\
\text { Tratados } \\
\text { Internacionales en } \\
\text { materia laboral } \\
\text { ratificados por México } \\
\text { Ley Federal del Trabajo } \\
\text { Contratos de Trabajo } \\
\text { Contratos-Ley } \\
\text { Reglamentos de Trabajo }\end{array}$ & $\begin{array}{l}\text { Artículo } 123 \text { Apartado A, fracción } \\
\text { XXIX Apartado B, fracción XI y XIII. } \\
\text { Los Tratados internacionales en } \\
\text { materia de seguridad social } \\
\text { ratificados por México } \\
\text { Ley del Seguro Social de } 1973 \\
\text { Ley del Seguro Social de } 1997 \\
\text { Ley del Instituto del Fondo } \\
\text { Nacional de la Vivienda para los } \\
\text { Trabajadores. } \\
\text { Ley del Instituto de Seguridad y } \\
\text { Servicios Sociales de los } \\
\text { Trabajadores al Servicio del Estado } \\
\text { Ley del Instituto de Seguridad } \\
\text { Social para las Fuerzas Armadas } \\
\text { Mexicanas } \\
\text { Reglamentos de las leyes de } \\
\text { seguridad social } \\
\text { Contratos de Trabajo, Contratos- } \\
\text { Ley } \\
\text { Acuerdos Generales dictados por } \\
\text { los organismos de seguridad social } \\
\text { Circulares dictadas por la Comisión } \\
\text { Nacional del Sistema de Ahorro } \\
\text { para el Retiro }\end{array}$ \\
\hline
\end{tabular}

Fuente: Elaboración propi con base en la Ley Federal del Trabajo, la Ley del Seguro Social y la Ley del Instituto de Seguridad y Servicios Sociales de los Trabajadores del Estado, México, 2018. 
Las disimilitudes que hay entre los conflictos laborales y los conflictos de seguridad social aunadas al fenómeno de la globalización y las crisis financieras de los institutos de seguridad social, ameritan que los órganos encargados de tramitar y resolver las controversias de seguridad social tengan conocimientos especializados en el derecho de la seguridad social, el derecho fiscal, el derecho laboral, el derecho bancario $\mathrm{y}$ bursátil, indispensables todos ellos, para comprender el nuevo paradigma que impera en el sistema de seguros básicos ante la hegemonía de las distintas aseguradoras, las Administradoras de Fondos para el Retiro y sus Sociedades de Inversión Especializadas de Fondos para el Retiro, cuya organización, funcionamiento y actual problemática escapan del ámbito de validez personal de la legislación laboral.

De ahí que la exigencia del conocimiento teórico--práctico del derecho laboral que se exige al personal en proceso de adscripción a los tribunales laborales dependientes del Poder Judicial de la Federación o a los poderes judiciales locales en términos del artículo 123 constitucional, apartado A, fracción XX. En disposición contraria a lo planteado inicialmente, será insuficiente si a nivel práctico, a los tribunales del poder judicial se les otorga competencia para resolver las múltiples y diferentes controversias que plantean los asegurados, pensionados y beneficiarios contra el Instituto Mexicano del Seguro Social, el Instituto de Seguridad y Servicios Sociales de los Trabajadores al Servicio del Estado, las Administradoras de Fondos para el Retiro y el Instituto del Fondo Nacional de la Vivienda para los Trabajadores.

Conviene traer a colación las esclarecedoras palabras del maestro Buen Lozano, 1995, p. IX):

Una deformación antigua de los conceptos ha asociado históricamente al derecho del trabajo con el derecho de la seguridad social.
Los planes de estudio de las universidades suelen colocarlos juntos, a veces en la compañía comprometedora del derecho burocrático, en una especie de síntesis de lo más importante del derecho social. Por el mismo motivo se ha considerado, por supuesto que, sin razón, que ser laboralista lleva en sí mismo el germen de la seguridad social. Nada más falso.

Ahora bien, en lo referente a la creación del Tribunal Especializado en materia de seguridad social dependiente del Poder Judicial de la Federación para resolver los conflictos de seguridad social, como lo propone la iniciativa de los senadores Tereso Medina e Isaías González, es lo más adecuado ante la especial naturaleza y características de este tipo de controversias, empero es desafortunada su creación bajo el marco jurídico de la Ley Federal del Trabajo, en la que conforme a la iniciativa propuesta, ni siquiera se detalla la forma de integrarse y las atribuciones que tendría este nuevo organismo.

Como se ha venido señalando, la legislación laboral reglamenta las relaciones laborales en términos del apartado A del artículo 123 constitucional, es decir, aquellas que primordialmente tienen lugar entre los trabajadores y los patrones pertenecientes a la iniciativa privada, por lo que la creación del organismo especializado en resolver las controversias de seguridad social se encuentra fuera del objeto para el cual se expidió y opera la legislación laboral.

$\mathrm{Al}$ concretarse el traslado de competencias para impartir la justicia laboral, de los órganos que dependen del ejecutivo federal a los ámbitos jurídicos del Poder Judicial de la Federación o al de los poderes judiciales locales; haciéndose necesaria, la inclusión de los jueces laborales o los que se adscriban al tribunal especializado en materia de seguridad social con sus respectivas atribuciones, dentro de los artículos 94, 97, 
116 fracción III, y 122 apartado A, fracción IV de la Constitución mexicana que corresponden al capítulo que reglamenta la integración y atribuciones del poder judicial, así como en la Ley Orgánica del Poder Judicial de la Federación, y no dentro de la Ley Federal del Trabajo. Asimismo, ante la instauración de los tribunales laboral dependientes del Poder Judicial Federal resulta necesaria la reforma de los artículos 294 y 295 de la Ley del Seguro Social, así como el artículo 53 de la Instituto del Fondo Nacional de la Vivienda para los Trabajadores, en cuyo contenido de forma conjunta se establece la competencia de la Junta Federal de Conciliación y Arbitraje para tramitar y resolver las controversias de seguridad social,

Es así, que, en virtud de lo expuesto, se considera necesaria la reforma al artículo 123 constitucional para que se realice el reconocimiento constitucional de los conflictos de seguridad social y que, a la autonomía didáctica, autonomía científica o dogmática y la autonomía legislativa del derecho de la seguridad social se agregue la autonomía procedimental y jurisdiccional. Y es que a pesar que dentro de las leyes de seguridad social, como la Ley del Seguro Social y la Ley del Instituto de Seguridad y Servicios Sociales de los Trabajadores del Estado con sus correspondientes normas reglamentarias, se consignan las prestaciones que derivan de los distintos seguros sociales y los requisitos para acceder a los mismos, se carece normas de tipo adjetivo u operativo en las que se reglamente el procedimiento para la interposición, tramitación y resolución de las controversias de seguridad social, además del procedimiento para la ejecución de las sentencias, evitándose con ello, su regulación en la Ley Federal del Trabajo, cuya referencia y aplicación sólo debiera hacerse de manera supletoria, esto es, en lo no previsto en las normas especializadas en materia de seguridad social.
En cuanto a la autonomía jurisdiccional resulta indispensable instituir los tribunales de lo social, a los que debiera otorgarse competencia, a nivel constitucional, para resolver todo tipo de controversias de seguridad social interpuestas contra cualquier organismo de seguridad social o en contra del Instituto del Fondo Nacional de la Vivienda para los Trabajadores, así como los conflictos que se interponen en contra de las aseguradoras o de las Administradoras de Fondos para el Retiro al tener a su cargo la administración de los recursos de la cuenta individual de los derechohabientes, lo que evitaría que autoridades como la Junta Federal de Conciliación y Arbitraje, el Tribunal Federal de Conciliación y Arbitraje y el Tribunal Federal de Justicia Administrativa se encarguen de resolver los conflictos de seguridad social bajo procedimientos de índole procesal laboral, procesal burocrática y administrativa que no corresponden con la naturaleza de las prestaciones de seguridad social.

Un aspecto fundamental en la justiciabilidad de los derechos que derivan de los sistemas de seguridad social, lo es el cabal y oportuno cumplimiento de las sentencias que emitan los tribunales dependientes del Poder Judicial Federal o de los poderes judiciales de las entidades federativas en contra de los institutos de seguros sociales, al tratarse de una parte fundamental de los derechos al debido proceso y de tutela judicial efectiva, pues éste último no culmina con el dictado de la resolución, sino involucra todo el proceso de ejecución de la misma, lo que da expresión a la vinculación entre los derechos judiciales y la protección judicial.

La Comisión Interamericana de Derechos Humanos se ha ocupado de subrayar ciertos rasgos distintivos de un proceso de ejecución de sentencia, cuando aquél que debe cumplimentarla no es otro que el Estado. De esta manera, el órgano interamericano ha reiterado que el deber estatal en garantizar la 
observancia de los fallos judiciales, alcanza particular importancia cuando quien debe cumplir la sentencia es un órgano del poder ejecutivo, legislativo o judicial, provincial o municipal, de la administración central o descentralizada, de empresas o institutos públicos, o cualquier otro órgano similar. Lo anterior se debe a que tales órganos, al ser estatales, suelen tener privilegios procesales, a usar su poder y sus privilegios para tratar de ignorar las sentencias judiciales dictadas en contra de ellos. (Comisión Interamericana de Derechos Humanos, 2007, p. 5).

Precisamente en el caso del Instituto Mexicano del Seguro Social, al haberse decretado en 2018, la inembargabilidad de sus cuentas bancarias ante la inscripción definitiva en el Sistema de Registro de Cuentas Bancarias de la Tesorería de la Federación en términos del artículo 17 de la Ley de la Tesorería de la Federación en correlación con el artículo 4 del Código de Procedimientos Civiles aunada a la exigencia de prolongados trámites administrativos que se imponen a los asegurados o sus beneficiarios para lograr la inclusión a nómina y que puedan cobrar de forma administrativa las pensiones decretadas en juicio, en lugar de que sea el organismo de salud, que fue condenado el que se encargue de tal cometido, resulta prioritario la instauración e instrumentación de un procedimiento dentro de las leyes de seguridad social para cumplimentar las resoluciones dictadas en juicio.

Una posible parte del procedimiento de ejecución, de acuerdo con Francisco Cuevas (2012, p. 430), podría ser el tipificar en la Ley del Presupuestos de Egresos de cada año una partida específica para las autoridades responsables $\mathrm{y}$, cuando se emita una resolución y éste haya causado estado, pero se omita cubrir a la parte actora las prestaciones condenadas o éstas le sean cubiertas administrativamente de manera incorrecta, la autoridad que decretó la condena le ordene directamente al responsable de dicha partida a que proceda a dar cumplimiento a la sentencia, sin ningún trámite administrativo interno de por medio, lo anterior ante la necesidad de que se otorguen con prontitud y oportunidad los beneficios de seguridad social, pues su finalidad es proteger al individuo de la adversidad o de proveerle los recursos necesarios cuando ésta ha tenido lugar.

\section{CONCLUSIONES}

Ante la innegable presencia e importancia que tienen los conflictos de seguridad social en los ámbitos económico, social y político del país, previa a la expedición de la legislación secundaria que reglamente la interposición, tramitación, resolución y ejecución de las controversias de seguridad social, es necesario que se reconozca en el texto constitucional, para que de esta manera conforme al principio de jerarquía normativa puedan ser adecuadas y reglamentadas en la Ley del Seguro Social y en la Ley del Instituto Ley del Instituto de Seguridad y Servicios Sociales de los Trabajadores del Estado, así como en sus correspondientes disposiciones reglamentarias, lo que favorecerá la justiciabilidad de las prestaciones de seguridad social ante la negativa de su otorgamiento o su indebida cuantificación realizada por los organismos de seguridad social, las aseguradoras o las Administradoras de Fondos para el Retiro.

Es necesario que se entienda, de una vez por todas, que el derecho laboral y el derecho de la seguridad social, si bien deben guiarse por los postulados de la justicia social y el derecho social, al tener instituciones jurídicas autónomas, marcos normativos propios, principios diversos así como una evolución y desarrollo diferentes deben regularse por sus propias normas sustantivas $\mathrm{y}$ adjetivas, encargándose la tramitación y resolución de los denominados conflictos individuales de seguridad social a organismos especializados 
en materia de seguridad social cuya naturaleza difiere de la materia laboral.

\section{REFERENCIAS}

Alexy, R. (2002). Teoría de los derechos fundamentales. Madrid: Centro de Estudios Políticos y Constitucionales.

Bernecker, W. L. (2004). Transición democrática y anomia social en perspectiva comparada. México: UNAMColegio de México-Servicio Alemán de Intercambio Académico.

Buen Lozano, N de. (1995). Seguridad Social, Mèxico: Porrúa.

Buen Lozano, N de. (2014). Derecho procesal del trabajo, México: Porrúa.

Comisión Interamericana de Derechos Humanos, El acceso a la justicia como garantía de los derechos económicos, sociales y culturales. Estudio de los estándares fijados por el Sistema Interamericano de Derechos Humanos, Washington, 7 de septiembre, 2007

Conflictos individuales de seguridad social. Estadísticas de la Junta Federal de Conciliación y Arbitraje. México, 31 de julio, 2017.

Cuevas Godínez, Francisco. (2012). El contencioso administrativo federal en México. En Juan Pablo Pampillo Baliño y, Manuel Alexandro Munive Páez (coords.), Derecho Administrativo, (pp. 407-436). México: Porrúa-Centro de Investigación e Informática Jurídica de la Escuela Libre de Derecho.

Decreto por el que se declaran reformadas y adicionadas diversas disposiciones de los artículos 107 y 123 de la Constitución Política de los Estados Unidos Mexicanos, en materia de justicia laboral. Diario Oficial de la Federación. México, 24 de febrero, 2018

Durkheim, E. (1998). El Suicidio. Buenos Aires: Grupo Editorial Tomo

Durkheim, E. (1998). La División del Trabajo Social. México: Colofón
Iniciativa con proyecto de Decreto por el que se reforman la Ley de Amparo, adecuando la reforma del artículo 107 constitucional a su ley reglamentaria y la Ley Federal del Trabajo, senador Luis Sánchez Jiménez. Cámara de Diputados. México, 2017

Iniciativa con proyecto de decreto por el que se expide la Ley del Instituto Federal de Conciliación y Registro Laborales; y se reforman, adicionan y derogan diversas disposiciones de la Ley Federal del Trabajo, de la Ley Federal de Entidades Paraestatales; de la Ley Orgánica de la Administración Pública Federal; de la Ley del Seguro Social y de la Ley del Instituto del Fondo Nacional de la Vivienda para los Trabajadores, en materia de justicia laboral, senador Tereso Medina Ramírez e Isaías González Cuevas. Cámara de Diputados. México, 7 de diciembre, 2017

Iniciativa con Proyecto de Decreto por el que reforman y adicionan diversas disposiciones de las Leyes Federal del Trabajo, del Seguro Social y del Instituto de Seguridad y Servicios Sociales de los Trabajadores del Estado, senadores Pilar Ortega Martínez, Teresa Medina Ramírez, Ernesto Cordero Arroyo y Miguel Ángel Chico Herrera. Cámara de Diputados. México, 15 de febrero, 2018

Kelsen, Hans. (1995). Teoría Pura del Derecho. México: Porrúa

Ley Federal del Trabajo (Reforma 2015). Recuperado de http://www.diputados.gob.mx/LeyesBibl io/index.htm México, 22 de marzo, 2018

Ley del Seguro Social. Diario Oficial de la Federación. México, 1ำ de julio, 1997

Exposición de Motivos de la Iniciativa de Decreto por el que se reforman y adicionan diversas disposiciones de la Constitución Política de los Estados Unidos Mexicanos, en materia de justicia laboral. México, 28 de abril, 2016

López Ayllón, Sergio. (2015). Justicia Cotidiana, Síntesis del informe y de las 


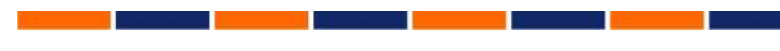

recomendaciones en materia de justicia cotidiana. México: Centro de Investigación y Docencia Económica, A.C.

Martínez Martínez, V. L. (2015). Conflictos individuales de Seguridad social. Desaciertos e incompetencia de su resolución. Revista Latinoamericana de Derecho Social, (número 21), juliodiciembre, pp. 121-149.

Organización Internacional del Trabajo. (1984). Introducción a la seguridad social, Ginebra: OIT.
Ruiz Moreno, Á. G. (2013). Nuevo derecho de la seguridad social. México: Porrúa.

Sánchez Castañeda, Alfredo y Reynoso Castillo, Carlos. (2013), La nueva legislación laboral mexicana. México: UNAM-Instituto de Investigaciones Jurídicas.

Suprema Corte de Justicia de la Nación. (2012). Las garantías de seguridad jurídica. México: SCJN. 